\title{
THE TIME VARIABLE IN THE CALCULATION OF BUILDING STRUCTURES. HOW TO EXTEND THE WORKING LIFE UNTIL THE 100 YEARS?
}

\author{
Authors: T. Cabrera (1), M. de las Heras (2), C. Cabrera (3), and A. M. de las Heras (4)
}

(1) Departamento 5420. E U Arquitectura Técnica. UPM, tomas.cabrera@upm.es

(2) Departamento 5405. E U Arquitectura Técnica. UPM, mariano.delasheras@upm.es

(3) E U Arquitectura Técnica. UPM, carolina.cmertens@alumnos.upm.es

(4) Grupo Investigación GIEPPE. UPM, delasheras.arq@telefonica.net

\section{ABSTRACT}

The idea that a building and consequently its structure is for a lifetime has stopped being a reference. CTE establishes that the life utility of a normal construction structure should be of 50 years.

If the time variable is introduced in the calculation of actions on structures, seems evident that different values can be used for a standard building, for a provisional structure with $\leq 10$ years of life utility or for a monumental building with a life utility of 100 years.

Table 1 Indicative design working life (Eurocode EN-1990)

\begin{tabular}{|c|c|l|}
\hline $\begin{array}{c}\text { Design working } \\
\text { life category }\end{array}$ & $\begin{array}{c}\text { Indicative design } \\
\text { working life } \\
\text { (years) }\end{array}$ & \multicolumn{1}{|c|}{ Examples } \\
\hline 1 & 10 & Temporary structures (1) \\
\hline 2 & 10 to 25 & $\begin{array}{l}\text { Replaceable structural parts, e.g. gantry girders, } \\
\text { bearings }\end{array}$ \\
\hline 3 & 15 to 30 & Agricultural and similar structures \\
\hline 4 & 50 & Building structures and other common structures \\
\hline 5 & 100 & $\begin{array}{l}\text { Monumental building structures, bridges, and other } \\
\text { civil engineering structures }\end{array}$ \\
\hline & $\begin{array}{l}\text { (1) Structures or parts of structures that can be dismantled with a view to being re-used should } \\
\text { not be considered as temporary. }\end{array}$ \\
\hline
\end{tabular}

The present presentation follows at all moment, the directives and formulations given in the different structural Eurocodes, till the moment not included in the CTE.

Finally the values of the actions that must be used to extend the life utility of a building until 100 years will be deduced, also it suitability and economic feasibility will be discuss.

\section{INTRODUCTION}

Since the publication of the Código Técnico de la Edificación (CTE) [1] in 2006, security in the evaluation of actions affecting the building structures must be done following the directives marked by the Eurocode [2].

In Europe the organization in charge of the standardization in the structure field is the European Committee for Standardization (CEN).

CEN State members are: Austria, Belgium, Bulgaria, Croatia, Cyprus, Czech Republic, Denmark, Estonia, Finland, France, Germany, Greece, Hungary, Iceland, Ireland, Italy, Latvia, 
Lithuania, Nederland, Norway, Poland, Portugal, Romania, Slovakia, Slovenia, Spain, Sweden, Switzerland, The former Yugoslav Republic of Macedonia, Turkey and United Kingdom.

CEN afíliate countries are:

Albania, Armenia, Azerbaijan, Belarús, Bosnia y Herzegovina, Egypt, Georgia, Israel, Jordan, Lebanon, Libya, Republic of Moldava, Montenegro, Morocco, Serbia, Tunisia, Ukraine.

The acceptance of an unify International regulation in the calculations of structures that reaches around five hundred million persons, got a huge importance both on a human scale and in terms of profession inside of what we designate as globalization.

The idea that a building and consequently its structure is for a lifetime, that is to say without temporal limit comparing it with the human lifespan, has stopped being a reference. CTE establishes that the life utility of a normal construction structure should be of 50 years.

In general the introduction of security in the actions of a building structure is achieved by multiplying its representative values with partial security coefficients named " $\gamma$ " and combination coefficients named " $\Psi$ ".

The calculation situations covered by CTE and the Eurocodes, are three:

a/ Persistent or transient. b/ Accidental. c/ Seismic.

If the time variable is introduced in the calculation of actions on structures, seems obvious that different values can be used for actions on standard structures or on temporary structure with a life utility of $\leq 10$ years or for a monumental building with an agreed life utility of 100 years.

The present communication studies in depth the value of the actions that act on a structure according to the life utility it was initially designed for, specially when it is interesting that its life utility gets higher than the standard. The methodology used in this Communications follows at all moment, the directives and formulations given in the different structural Eurocodes, till the moment not included in the CTE. The quantitative importance of the persistent actions and the different variable climatic actions that act on a building structure, will be studied separately

\section{The actions on structures and their combinations.}

The actions are defined as permanent $(G)$, variables $(Q)$ y prestress $(P)$. For last limit stats (ELU) the following expression must be used:

$$
\sum_{\mathrm{j} \geq 1} \gamma_{\mathrm{G}, \mathrm{j}}{ }^{*} \mathrm{G}_{\mathrm{k}, \mathrm{j}}+\gamma_{\mathrm{P}}{ }^{*} \mathrm{P}+\gamma_{\mathrm{Q}, 1}{ }^{*} \mathrm{Q}_{\mathrm{K}, 1}+\sum_{\mathrm{i}>1} \gamma_{\mathrm{Q}, \mathrm{i}}{ }^{*} \psi_{0, \mathrm{i}}{ }^{*} \mathrm{Q}_{\mathrm{k}, \mathrm{i}}
$$

Where: $\gamma_{G, j}$ is the security coefficient for permanent actions, $\gamma_{P}$ is the security coefficient for prestress actions, if there is, $\gamma_{Q, 1}$ is the security coefficient for the leading variable action and $\gamma_{Q, i}$ corresponding to the concomitant variable actions (accompanying the leading one)

$G_{k}$ is the characteristic value of each permanent action, $P$ is the characteristic value of the prestress action, $Q_{k}$ is the characteristic value of each variable action and $\psi_{0, i}$ the combination coefficient (simultaneity) for the concomitant variable actions (all of them well defined in the regulation). When the life of a structure differs from the standard value, it is possible to act according to any of these options:

$1 /$ Define the different partial security coefficients $\gamma$ according to the life utility. 
2/ Define the different combination coefficients $\psi_{0, i}$ according to the life utility.

3/ Distinguish the different characteristic values of the actions according to the life utility.

The Eurocode is defined by the latter one and thus the guide of this study.

\section{The agreed security in structures. (UNE- EN 1900).}

In the calculation of structures and for its different last limit stats three levels referred to structural security are identified, these levels are:

-Level I: Semi probabilistic methods. Defined (in a structural code) by the characteristic value of the actions.

Probabilistic methods can be subdivided in two types:

-Level II: first order reliability methods called FORM. These methods make use of certain well defined approximations and lead to results which in most structural applications can be considered as precisely enough. This is the level at which our presentation will be developed.

- Level III. Fully probabilistic methods (exact probabilistic calculation). Methods at level III are barely used in the calibration of calculation codes due to the significant shortage of reliable statistical data.

\section{$4 \quad$ The probability of a structural failure and rate of reliability $\beta$.}

In proceedings of level II a measure of reliability is conventionally defined through the so called rate of reliability " $\beta$ ". Rate that EN 1990 relates with the failure probability "Pf" through the cumulative distribution function of the normal distribution function " $\varnothing$ ". Also incorporating, now, the structural life utility, to complete the information obtained from the values of Table 2.

Table 2 Failure probability and life utility.

\begin{tabular}{|c|c|c|c|c|c|c|}
\hline$P \mathrm{f}=\emptyset^{*}(-\beta)$ & $1,4 * 10^{-6}$ & $7,2 * 10^{-6}$ & $1,4 * 10^{-5}$ & $3,6 * 10^{-5}$ & $\mathbf{7 , 2} * \mathbf{1 0}^{-5}$ & $1,4 * 10^{-4}$ \\
\hline$\beta$ & 4,7 & 4,3 & 4,2 & 4,0 & $\mathbf{3 , 8}$ & 3,6 \\
\hline Years & 1 & 5 & 10 & 25 & $\mathbf{5 0}$ & 100 \\
\hline
\end{tabular}

\section{$5 \quad$ Calibration of characteristic values of calculation of the actions.}

EN-1990 (Annex C.7) indicates the distribution functions recommended to modify the characteristic value of the defined action in a code, like CTE.

Table 3 Design values for various distribution functions

\begin{tabular}{|l|c|}
\hline Distribution & Design values \\
\hline Normal & $\mu-\alpha \beta \sigma$ \\
\hline Lognormal & $\mu \exp (-\alpha \beta V)$ for $V=\sigma / \mu<0,2$ \\
\hline Gumbel & $u-\frac{1}{a} \ln \{-\ln \Phi(-\alpha \beta)\}$ \\
& where $u=\mu-\frac{0,577}{a} ; \quad a=\frac{\pi}{\sigma \sqrt{6}}$ \\
\hline
\end{tabular}

\section{$6 \quad$ Permanent actions.}

We consider a permanent action for example an own weight $G$ which follows a normal distribution. In this case we use de following formula: 


$$
G=\mu-(\alpha * \beta * \sigma)
$$

When in the verification of the reliability of a structure an alternative period of time is used $T_{\mathrm{a}}$ in stead of the stipulated life utility $T_{\mathrm{d}}$, then the value of calculation $G$ must be determined through $T_{\mathrm{a}}$ instead of $T_{\mathrm{d}}$. The characteristic value $G_{\mathrm{k}}$ of $G$ is defined, for a permanent action, as its average value $\mu_{G}$, that is to say:

$$
G_{K}=\mu_{G}
$$

The value of calculation $G_{d}$ is given by the expression:

$$
G_{\mathrm{d}}=\mu_{G}-\left(\alpha_{G} * \beta * \sigma_{G}\right)=\mu_{G}-(-0,7) * \beta * \sigma_{G}=\mu_{G} *\left[1+0,7 * \beta * V_{G}\right]=G_{K} *\left[\gamma_{G}\right]
$$

Where: $\mu_{G}$ is the average. $\sigma_{G}$ is the standard deviation. $V_{G}$ the variation coefficient (in statistics, the variation coefficient is defined as en $V=\sigma / \mu \mid$ ).

$\alpha_{G}=-0,7$ is the sensitivity coefficient of $G$ in the FORM method.

The partial security coefficient of $G$ is defined by: $\gamma_{G}=G_{d} / G_{k}$

After the expressions (ec.4) and (ec.5) we obtain: $\gamma_{G}=1+0,7 * \beta^{*} V_{G}$ )

With $\beta=3,8$ and with a usual variation coefficient for permanent actions $V_{G}=0,1$ then we have: $\gamma_{G}=1+(0,7 * 3,8 * 0,1)=1,266$

EN-1990 increases security approximately a $5 \%$ to consider the possible uncertainty of the model, then: $\gamma_{G}=1,05 * 1,266=1,33 \approx 1,35$

That results to be the value recommended by en EN-1990 and CTE.

Figure 1 Permanent action graphic

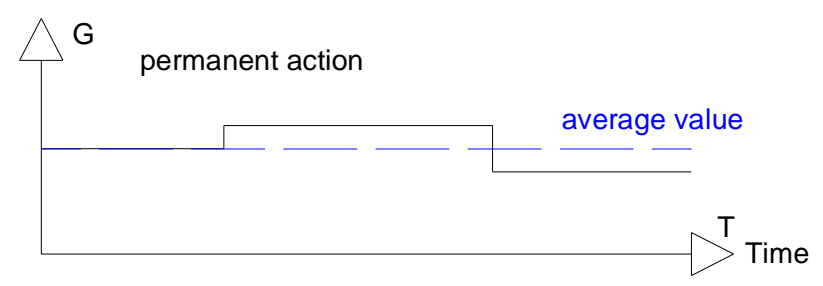

Now we will evaluate the security for a different period. In our case we will take the variable of time up to a century.

With $\beta=3,6$ (100 years): $\gamma_{G}=1,05 *(1+0,7 * 3,6 * 0,1)=1,31<1,35$

As it can be seen and contrary to expectations it results a smaller value than the previously calculated, with an approximated saving of a $3 \%$.

\section{$7 \quad$ Variable actions.}

In the variable actions with a return period different from the standard value of 50 years we will study the climatologically actions: snow, wind and temperature.

\subsection{Snow climatic action.}

In accordance with EN 1991-1-3 snow loads, in Annex D, indicates that the characteristic value of the snow action $s_{k, n}$ for a return period $f$ "n" years, is given by: $s_{n}=\boldsymbol{X}{ }^{*} s_{k}$,

Where: $\quad \boldsymbol{X}=\frac{1-V \frac{\sqrt{6}}{\pi}[\ln (-\ln (1-p))+0,57722]}{1+2,5923 V}$ 
$s_{\mathrm{k}}$, characteristic value of snow load for a return period of 50 years.

$s_{, n}$, is the value of the snow load for a return period of " $n$ " years.

$p$, is the probability of annual leave. For very small probabilities it is approximately equivalent to $1 / n$. Where " $n$ " is the corresponding return period in years. (For example for $n=50$ years, then $1 / \mathrm{n}=0,02$ and consequently $p=0,02$ ).

$V$, is the variation coefficient for the maximum annual snow loads. ( $V=0,2$ has been taken for the examples of comparison of the table 4)

Figure 2 Variable action graphic

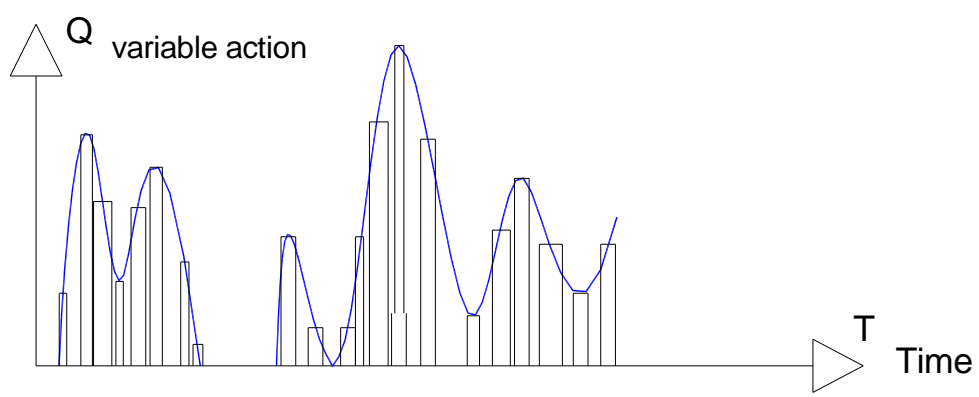

\subsection{Wind climatic action.}

EN 1991-1-4 Wind actions, indicates that the basic wind speed $v_{\mathrm{b}, n}$ for a return period of " $\mathrm{n}$ " years [not to be confused with the superscript $n$ of the formula (11)] can be determined by using the formula : $v_{\mathrm{b}, n}=c$ cprob ${ }^{*} v_{\mathrm{b}, 50}$,

Where: $\quad c p r o b=\boldsymbol{X}=\left[\frac{1-K \ln [-\ln (1-p)]}{1-K \ln [-\ln (0,98)]}\right]^{n}$

$v_{\mathrm{b}, 50}$ is the Basic wind speed for a return period of 50 years (average wind speed during 10 min. with an annual probability of being exceeded of 0,02 , so to say $p=0,02$ ).

$v_{\mathrm{b}, n}$ for a return period of " $\mathrm{n}$ " years, $\mathrm{p}$ is the probability for $v_{\mathrm{b}, n}$ to exceed the return period of "n" years.

According to EN-19991-1-4: The values of $K$ can be provided by a national annex. (The recommended values by the standard are: $\mathrm{K}=0,2$ y $n=0,5)$.

For the examples of comparison (table 4 ) it is consequently used: $K=0,2$ (corresponding to the variation coefficient $V_{v}=0,26$ ) and $n=0,5$.

\subsection{Temperature climatic action.}

According to EN 1991-1-5 Thermal actions in Annex A, indicates the maximum and minimum air temperature in the shade $T_{\max } / T_{\min }$, for a return period of 50 years. For different return periods of "n" years:

$$
\begin{aligned}
& T_{\text {max }, p}=X^{*} T_{\max }, \quad \text { for } \quad X=\left\{k_{1}-k_{2} \ln [-\ln (1-p)]\right\} \\
& T_{\min , p}=X^{*} T_{\min ,}, \quad \text { for } \quad X=\left\{k_{3}+k_{4} \ln [-\ln (1-p)]\right\}
\end{aligned}
$$

(Where: the equation 13 can only be used if $T_{\min }$ is negative).

$T_{\max , p} / T_{\min , p}$ is the maximum/minimum of the air temperature in the shade for an annual probability of being exceeded "p" different from 0,02 .

The recommended coefficients by EN-1991-1-5 are:

$k_{1}=0,781, k_{2}=0,056, k_{3}=0,393$, 
$k_{4}=-0,156$ (based on U.K. data)

$p$,is the annual probability of being exceeded for a return period of $n$ years.

The summary of the reduction coefficients $\boldsymbol{X}$ for climatic actions (applied un such a way: $Q_{\mathrm{k}, n}=X$ * $Q_{\mathrm{k}, 50}$ for the different return periods) Are summarizes in Table 4:

Table 4: Coefficients "X" of reduction for climatic actions $Q_{k, n}=X{ }^{*} Q_{k, 50}$ "

\begin{tabular}{|c|c|c|c|c|c|}
\hline \multirow{2}{*}{ Return period in years } & \multirow{2}{*}{$\mathrm{Pn}$} & \multicolumn{4}{|c|}{ Coefficient of reduction $\mathbf{X}$} \\
\cline { 3 - 6 } & & $S_{\mathrm{n}}$ & $v_{\mathrm{b}, n}$ & $T_{\max , p}$ & $T_{\min , p}$ \\
\hline 10 years & 0,100 & 0,83 & 0,90 & 0,91 & 0,74 \\
\hline 25 years & 0,040 & 0,93 & 0,96 & 0,96 & 0,89 \\
\hline 50 years & 0,020 & 1 & 1 & 1 & 1 \\
\hline 75 years & 0,013 & 1,04 & 1,02 & 1,02 & 1,07 \\
\hline $\mathbf{1 0 0}$ years & $\mathbf{0 , 0 1 0}$ & $\mathbf{1 , 0 7}$ & $\mathbf{1 , 0 4}$ & $\mathbf{1 , 0 4}$ & $\mathbf{1 , 1 1}$ \\
\hline
\end{tabular}

\section{Conclusions}

1 a - The characteristic value of permanent actions can be reduced if the life utility of a building structure is estimated in 100 years. If the principle of prudence is applied this saving may not be considered.

2 a - The characteristic value for climatic actions can be reduced when the life utility of a standard structural is shortened (life utility $<50$ years).

$3^{\text {a }}$.- The characteristic value for climatic actions should be increase when trying to extend the structural life utility up to 100 years. In this regard, the increase of the standard values is very small: For the snow action the increase is a $7 \%$, while the increase for the wind action is a $4 \%$. The temperature effect in a building is unimportant, because structures are usually very protected.

4 a For the death loads the Eurocode has not established a formulation yet. Since we use agreed values, for example in a school $3 \mathrm{kN} / \mathrm{m}^{2}$ in classrooms and $4 \mathrm{kN} / \mathrm{m}^{2}$ in corridors and accesses, we should consider using them without changes.

$5^{\mathrm{a}}$.- If we take the average value between the snow action and the wind action the resulting value is $5,5 \%$. If we evaluate that the joint action of both is less than the half of the sum of permanent actions plus the death loads, the economic overrun of taking the life utility of a structure up to 100 years should be less than $2 \%$.

\section{REFERENCES}

[1] Ministerio de Fomento: Código Técnico de la edificación. (2006). M F, Madrid, Spain.

[2] AENOR. Madrid. Eurocódigos estructurales: UNE-EN 1990: Eurocódigos. Bases de cálculo de estructuras. (2003). UNE-EN 1991-1-3: Eurocódigo 1. Cargas de Nieve (2004). UNE-EN 1991-1-4: Eurocódigo 1. Acciones de viento. (2007). UNE-EN 1991-1-5: Eurocódigo 1.Acciones térmicas. (2004). AENOR. Madrid, Spain.

[3] Holicky M. and Marková J. (2002). Reliability Differentiation. Leonardo da Vinci proyect. Czech Tecnical University of Prague, Czech Republic.

[4] Gulvanessian H. and Calgaro J-A. (2002). Designers' Guide to EN 1990, Eurocode basis of structural desing. Thomas Telford, United Kingdom 